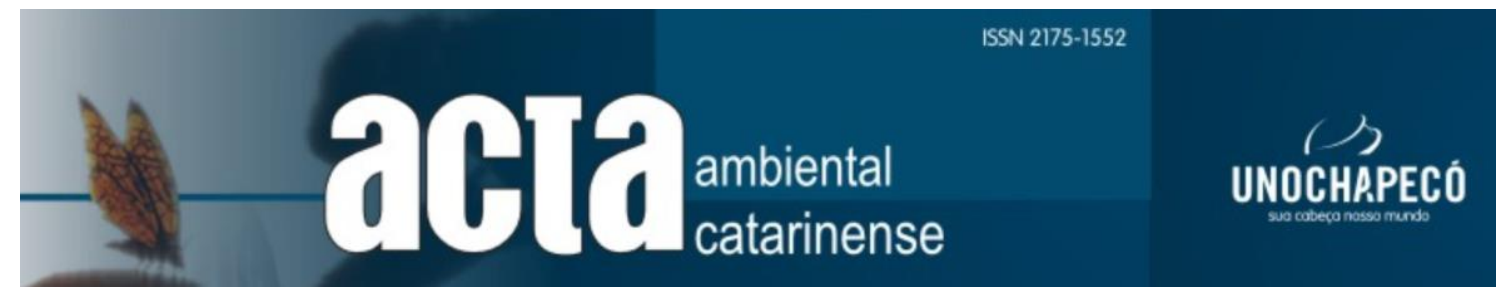

\title{
FEIRAS LIVRES: UM ESTUDO DE CASO RELACIONADO À DISPONIBILIDADE DE PLANTAS MEDICINAIS, AROMÁTICAS E CONDIMENTARES
}

\author{
Samuel Tadeu Tonin'; Deyze Cristina Lucas'; Amanda Fabres Oliveira Radunz²; Ítalo Kael Gilson'; Jacir Dal \\ Magro; Marjana Radunz4; Amanda Raquel Bizollo'; André Luiz Radunz5*
}

\author{
${ }^{1}$ Academico curso de agronomia Universidade Federal da Fronteira Sul, Campus Chapecó; \\ ${ }^{2}$ Doutoranta no Programa de Pós-graduação em Ciências da Saúde (UNOCHAPECÓ); \\ 3Professor no Programa de Pós-graduação Sctricto Sensu em Ciências Ambientais (UNOCHAPECÓ); \\ ${ }^{4}$ Doutoranda Programa de Pós-Graduação em Ciência e Tecnologia de Alimentos, Universidade Federal de Pelotas; \\ ${ }^{5}$ Professor Adjunto Universidade Federal da Fronteira Sul, Campus Chapecó
}

*E-mail: andre.radunz@uffs.edu.br

\begin{abstract}
Resumo
Objetivou-se avaliar a organização social das feiras livres frente a disponibilidade de mudas e partes secas vegetais de plantas medicinais, aromáticas e condimentares (MAC), ofertadas aos consumidores em feiras livres do município de Chapecó-SC. Os dados foram coletados visualmente através de visitas às feiras livres, em dois diferentes momentos. Os resultados demonstram que as feiras livres do município estão disposta em 10 espaços distintos dentro da área urbana, totalizando 16 momentos de realização distribuídos entre os dias da semana. De maneira geral, os espaços ofertam diversos produtos aos consumidores, entre os quais estão as espécies MAC tano na forma de mudas quanto de partes secas, esta última representando, em média, $72 \%$ do total. A oferta da maioria das espécies não foi influenciada pela data de avaliação, sendo as mais recorrentes a Ruta graveolens, Matricaria chamomilla, Rosmarinus officinalis, Aloysia citriodora, Mentha pulegium, Plectranthus barbatus, Citrus sinensis, Mikania glomerata, Helichysum italicum, Mentha sp., Artemisia absinthium, Salvia officinalis, Ocimum basilicum, Origanum majorana, Achyrocline satureioides, Malva sylvestris, sendo encontradas tanto em mudas como partes secas.
\end{abstract}

Palavras-chave: agricultura familiar, comercialização, plantas bioativas

\section{FREE FAIRS: A CASE STUDY RELATED TO AVAILABILITY OF MEDICAL, AROMATIC AND CONDIMENTAL PLANTS}

\begin{abstract}
The objective of this study was to evaluate the social organization of free markets in view of the availability of seedlings and dry parts of medicinal, aromatic and spice plants (MAC) offered to consumers in free markets in the municipality of ChapecóSC. Date were collected visually by visiting free markets at two different times. The results show that the free markets of the municipality are arranged in 10 different spaces within the urban area, totaling 16 times distributed between the days of the week. In general, the spaces offer a variety of products to consumers, including MAC species as seedlings and dry parts, the latter representing on average $72 \%$ of the total. The supply of most species was not influenced by the evaluation date, the most frequent being Ruta graveolens, Matricaria chamomilla, Rosmarinus officinalis, Aloysia citriodora, Mentha pulegium, Plectranthus barbatus, Citrus sinensis, Mikania glomerata, Helichysum italicum, Mentha sp., Artemisia absinthium, Salvia officinalis, Ocimum basilicum, Origanum majorana, Achyrocline satureioides, Malva sylvestris, being found in both seedlings and dry parts.
\end{abstract}


Keywords: family farming, marketing, bioactive plants

\section{Introdução}

Desde os tempos remotos o homem busca na natureza recursos e espécies vegetais para atender suas necessidades, como fonte de alimento, manejo de pragas e doenças e para o tratamento e cura de enfermidades (LUNA, 2006; PEREIRA e BERTONI, 2008; DAVID e PASA, 2015), bem como nas manifestações místicas e religiosas.

O cultivo e a utilização de plantas medicinais, aromáticas e condimentares (MACs), cada vez mais tem ocupado os espaços de discussões na pesquisa, ensino e extensão, e seus usos têm ganhado legitimação. Fato relacionado, entre outros, aos aspectos de conservação da natureza e dos conhecimentos tradicionais (LACERDA et al., 2013), a inserção destas espécies no Sistema Único de Saúde (SUS), a partir do Programa Nacional de Plantas Medicinais e Fitoterápicos (SCHIEDECK, 2016) e também nos manejos dos agroecossistemas produtivos das unidades familiares.

Neste cenário, para Silva e Moraes (2008) a agricultura familiar possui grande potencial para ser inserida nas discussões que envolvem as MACs, pois para os autores o mercado interno e externo de fitoterápicos vem crescendo anualmente e tem demonstrando a necessidade de organização do setor produtivo. Assim, a agricultura familiar pode se apropriar de espaços relacionados ao fornecimento de mudas de plantas MACs e também de suas partes vegetais, para serem utilizadas nas próprias propriedades, mas também pelas famílias do meio urbano, nos seus diferentes usos. Trata-se, portanto, de mais uma alternativa na geração de emprego e renda para este segmento tão importante e representativo do país (LOURENZANI et al., 2014).

Diante do exposto, as feiras livres ganham destaque, são espaços de abastecimento de alimentos nas cidades, especialmente as interioranas, que estimulam o desenvolvimento econômico, proporcionando a inclusão social e preservando hábitos culturais (COUTINHO et al., 2006). Permite, por sua vez, ao possibilitar um espaço de comercialização direta do produtor ao consumidor, contribuir para o reconhecimento da agricultura familiar enquanto categoria social, bem como fomentar os espaços de troca de saberes entre produtores e consumidores. Esse aspecto contribui para a qualidade de vida dos agricultores, sua reprodução econômica, social, cultural e também familiar, ofertando produtos de qualidade ao consumidor e, com isto, proporcionando o desenvolvimento da mesorregião de inserção do município. Ainda, nas feiras livres, as MACs podem ser comercializadas nas mais variadas formas, como ramos verdes, raízes, cascas, partes secas e também mudas (AGRA et al., 2008; LEITÃO et al., 2009; SANTOS et al., 2009).

Assim, cabe salientar a importância de pesquisas com as espécies MAC, bem como as que envolvem as feiras livres, pois poucos são os trabalhos que abordam esta temática, em especial para a região Oeste de Santa Catarina. Assim, objetivou-se com o presente trabalho avaliar a disponibilidade de mudas e partes secas vegetais de plantas medicinais, aromáticas e condimentares, em duas datas de avaliação, ofertadas aos consumidores nas feiras livres do município de Chapecó-SC.

\section{Material e Métodos}

A presente pesquisa é caracterizada como estudo de caso, através da utilização de instrumentos quanti-qualitativo de coleta de dados e também bibliográficos. Foram coletados dados sobre a localização das feiras livres e também os relativos às datas de ocorrência das mesmas no meio urbano do município de Chapecó - SC, a partir da revisão bibliográfica e acervos documentais do município. E a coleta de dados sobre a disponibilidade de MAC e suas partes secas a partir de visitas às feiras livres.

Considerando a sazonalidade das espécies cultivadas, primou-se pela realização da coleta de dados em dois momentos: o primeiro, realizado na primeira quinzena do mês de julho de 2016 e o segundo, na primeira quinzena do mês de setembro de 2016. A coleta dos dados foi realizada a partir de visitas em diferentes dias da semana e horários em que ocorrem as feiras no município de Chapecó-SC. A partir dos dados coletados foram elaboradas tabelas e figuras para melhor visualização dos resultados. Salienta-se ainda que a pesquisa foi realizada através de observações visuais da disponibilidade de mudas e partes secas das espécies medicinais, aromáticas e condimentares ofertadas nas bancas da feira livre. Utilizou-se, para apoio à identificação das espécies, livros da área de identificação de plantas e consulta ao site: http://floradobrasil.jbrj.gov.br/reflora/PrincipalUC/Principal UC.do;jsessionid=F0B6F4CD9223FD24ACD8289112F1954 3, administrado pelo Instituto de Pesquisas Jardim Botânico do Rio de Janeiro, em que são catalogados herbários de plantas coletadas no Brasil.

\section{Resultados e Discussão}

A partir das informações obtidas, através de revisão bibliográfica e a acervos documentais da Prefeitura Municipal de Chapecó, identificou-se 10 locais de feiras livres no meio urbano do município de Chapecó-SC, os quais compõem 16 momentos diferentes de realização das feiras, ou seja, alguns locais apresentam mais que uma data de feira por semana (Tabela 1). A diversidade no número de datas de feiras livres identificados proporciona ao consumidor, frequentador das feiras livres, maior comodidade e flexibilidade para optar por horários e locais que lhes são mais convenientes, fato que pode possibilitar a ampliação dos consumidores, uma vez que estes dispõem de maior oferta de feiras no espaço temporal e geográfico. 
Tabela 1. Locais, horários e dias em que ocorrem as feiras livres em Chapecó- SC, 2016.

\begin{tabular}{lllll}
\hline Locais & Terça & Quarta & Sexta & Sábado \\
\hline Calçadão & $07: 30-13: 30$ & & & $07: 00-12: 00$ \\
$\begin{array}{l}\text { Centro } \\
\text { Presidente }\end{array}$ & $07: 00-12: 00$ & & $07: 00-12: 00$ \\
$\begin{array}{l}\text { Médici } \\
\text { Parque das }\end{array}$ & $15: 00-19: 00$ & & $07: 00-12: 00$ \\
Palmeiras & & $07: 00-12: 00$ & & $07: 00-12: 00$ \\
Efapi & $15: 00-18: 00$ & & $07: 00-12: 00$ \\
São Cristóvão & $08: 00-10: 00$ & & $07: 00-12: 00$ \\
Loteamento & & $17: 00-$ & \\
Expoente & & $19: 30$ & \\
Bela Vista & & & $07: 00-9: 30$ \\
Cristo Rei & & & $07: 00-10: 00$ \\
Santo Antônio & & & $06: 30-10: 30$ \\
\hline
\end{tabular}

As feiras livres ocorrem de terça a sábado (Tabela 1), sendo observado que na terça são oferecidos dois horários de feira, sendo eles: Calçadão na parte da manhã e Bairro Presidente Médici à tarde. Já na quarta são oferecidas quatro opções de feira, assim composto: Centro, Parque das Palmeiras e Bairro São Cristóvão pela manhã e Bairro Efapi à tarde. Na sexta é oferecido apenas um horário à tarde, na feira que ocorre no Loteamento Expoente; neste local o horário de funcionamento inicia a partir das 17:00 horas, fato de relevância, pois possibilita aos consumidores um horário diferenciado para realizar suas compras na feira. Com relação ao sábado, dia em que mais ocorrem feiras livres no município, foram identificados pela manhã nove diferentes locais de feira, sendo que apenas no Loteamento Expoente a feira não é realizada no sábado.

Para Lourenzani et al. (2014), as feiras livres representam um curto canal de comercialização de plantas medicinais entre produtores e consumidores, sendo o preço cobrado negociado de acordo com a oferta e procura do produto, que é distinta ao longo do ano. O autor ainda salienta que, por se tratar de um canal curto, as margens de lucro são maiores, pois não são compartilhadas com outros agentes, representando, portanto, uma possibilidade de maiores rendimentos para o produtor.

No que tange aos dias da semana, em que ocorrem as feiras livres no município de Chapecó, pode-se verificar pela figura 1 que elas ocorrem na terça, quarta, sexta e aos sábados, sendo ofertados, respectivamente 2, 4, 1 e 9 horários diferentes.

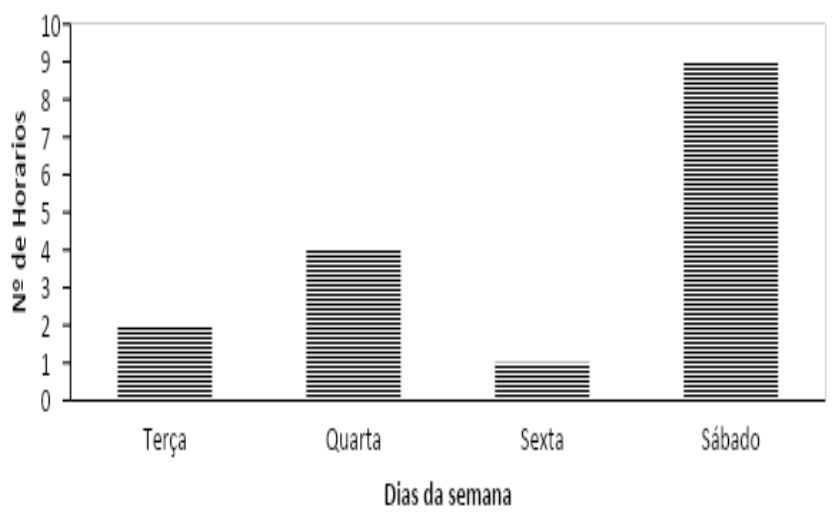

Figura 1: Número de horários para cada dia de feira livre no município de Chapecó - SC, 2016.

A partir da localização das feiras livres no município de Chapecó-SC, pode-se identificar que na região central da cidade há 2 locais de feira, Calçadão e Centro, sendo os demais distribuídos nos bairros do município (Efapi, São Cristóvão, Bela Vista, Cristo Rei, Santo Antônio, Expoente, Parque das Palmeiras e Presidente Médici), conforme figura 2. Neste sentido, após a determinação da localização e datas de ocorrência das feiras livres, avaliou-se a disponibilidade de plantas medicinais, aromáticas e condimentares e a forma de comercialização, plantas secas ou mudas disponíveis para comercialização nos diferentes locais e datas.

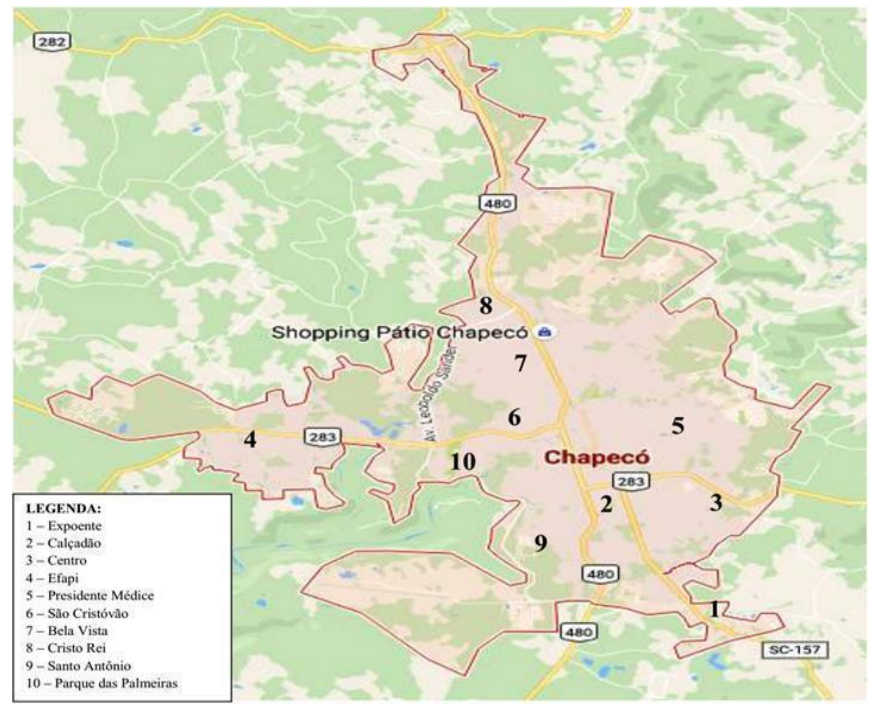

Figura 2: Mapa do município de Chapecó-SC e localização das feiras livres, 2016. Expoente (1), Calçadão (2), Centro (3), Efapi (4), Presidente Médici (5), São Cristóvão (6), Bela Vista (7), Cristo Rei (8), Santo Antônio (9), Parque das Palmeiras (10). Fonte: Google Maps.

Com relação ao levantamento realizado sobre a disponibilidade para comercialização de espécies MAC, tanto na forma de planta seca quanto de mudas, verificou-se na 
primeira avaliação, que dos 10 locais de feira livre, em apenas 5 alguma espécie de MAC é ofertada ao consumidor, sendo eles: Centro, Calçadão, Efapi, Presidente Médici e São Cristóvão (Figura 3). Desses 5 locais de feira, foram identificadas 27 espécies vegetais na forma de mudas e 75 na forma de plantas secas, representando, respectivamente, $26 \mathrm{e}$ $74 \%$ do total das espécies comercializadas nestes espaços. Em alguns casos as espécies se repetem, pois algumas são ofertadas ao consumidor tanto na forma de mudas quanto de planta seca.

Conforme se pode observar na figura 3, para o segundo momento da pesquisa, a qual ocorreu na primeira quinzena do mês de setembro de 2016, houve redução na oferta de espécies MAC, tanto na forma de plantas secas como em mudas. Foi observada a ocorrência de 32 espécies na forma de mudas e 55 espécies na forma de planta ou parte seca, correspondendo, respectivamente a $37 \%$ e $63 \%$ do total de espécies. Da mesma forma que na primeira avaliação, algumas espécies se repetem na forma de muda e plantas secas.

\section{sPartes secas $\quad$ III Mudas}

(A)

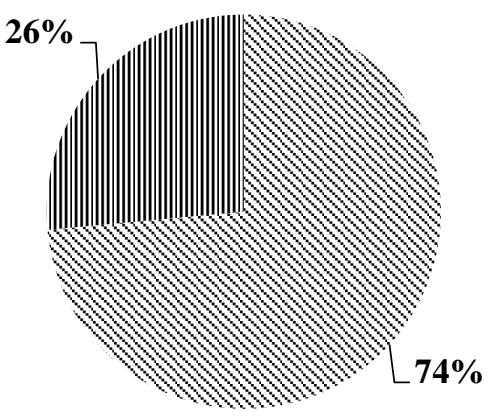

$$
\text { II Partes secas Mudas }
$$

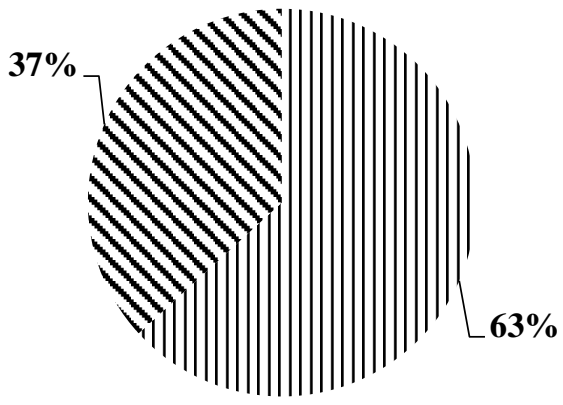

Figura 3: Quantidade de espécies medicinais, aromáticas e condimentares e suas formas de comercialização, mudas ou partes secas, nos dois momentos de avaliação, mês de julho (A) e mês de setembro (B), nas feiras livres de Chapecó - SC, 2016.
Assume-se que a diferença na oferta de espécies MAC aos consumidores, entre o primeiro e o segundo momento de avaliação possa estar associado à sazonalidade dos cultivos agrícolas, bem como a procura ou preferência do consumidor e ainda ao período em que foi realizada a avaliação, em virtude da ausência das MAC por fatores ambientais. Conforme também destacado por Lourenzani et al. (2014), algumas das espécies de plantas medicinais possuem época especifica durante o ano para produção e consumo.

Guisleni (2012), avaliando as feiras livres no Rio Grande do Sul, identificou que em média os agricultores destinam de 0,5 a 2,5 ha para o cultivo de plantas MAC, não sendo esta à principal atividade e representando, aproximadamente, apenas $3,6 \%$ na renda familiar desses agricultores. Fato que pode também ocorrer em Santa Catarina, o que explicaria à baixa disponibilidade de locais que dispõem das MACs, em relação ao número de feiras livres no município de Chapecó.

Somando-se os dois momentos da pesquisa foram encontradas nas feiras livres 59 espécies de mudas o que corresponde a $31 \%$ e 130 espécies de drogas vegetais o que equivale a $69 \%$ das espécies MAC que estavam a disposição do consumidor no momento da pesquisa (figura 4), cabe salientar que por vezes as espécies se repetem na forma de mudas e partes secas. Pode-se atribuir estes valores devido à praticidade que as MAC na forma de partes secas apresentam, pois não são todas as pessoas que dispõem de espaço e tempo para cultivar estas espécies, mesmo sendo em pequenos ambientes. Na forma de planta seca o consumidor pode armazená-las, em locais adequados, por períodos relativamente longos, sem que percam suas propriedades medicinais, aromáticas ou condimentares.

\section{Partes secas $\equiv$ Mudas}

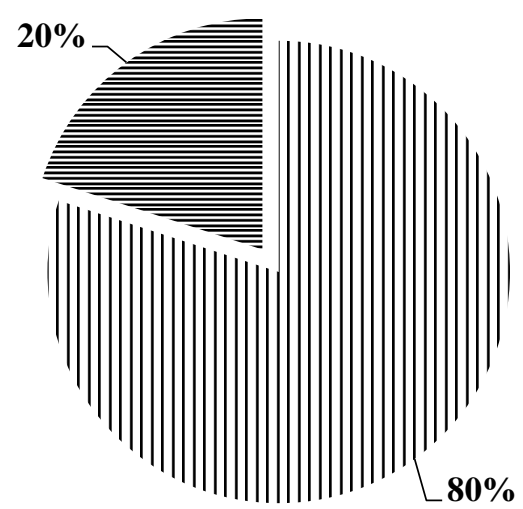

Figura 4: Redução na oferta de espécies MAC nas feiras, comparando-se os dois momentos da avaliação, julho e setembro, Chapecó - SC, 2016.

Observando-se os dois momentos da pesquisa, percebemos que houve redução na oferta de plantas MACs, quando comparado o mês de julho em relação a setembro. Foi 
possível constatar a redução de 5 espécies de mudas e 20 espécies de partes secas de julho para setembro, o que corresponde, respectivamente, a uma redução de $20 \%$ e $80 \%$ no número de espécies MAC. Atribui-se esta redução, possivelmente, a fatores relacionados à preferência ou procura pelo consumidor no momento da pesquisa, bem como os associados à sazonalidade e também adversidades climáticas.

Com relação à disponibilidade das espécies de MAC, é possível verificar, a partir da tabela 2 , que a grande maioria das espécies foi encontrada nos dois momentos da pesquisa, sendo ofertadas como plantas secas ou mudas. Considerando que várias das espécies se repetem na forma de comercialização, ao final, somam um total de 88 diferentes espécies de MACs.

Entre as espécies de MACs mais recorrentes estão: Ruta graveolens, Matricaria chamomilla, Rosmarinus officinalis, Aloysia citriodora, Mentha pulegium, Plectranthus barbatus, Citrus sinensis, Mikania glomerata, Helichysum italicum, Mentha sp., Artemisia absinthium, Salvia officinalis, Ocimum basilicum, Origanum majorana, Achyrocline satureioides, Malva sylvestris, sendo encontradas tanto em mudas como partes secas.

A diversidade de espécies vegetais ofertadas aos consumidores das feiras livres de Chapecó demonstra que, conforme destacado por Almeida (2003), nas ultimas décadas o uso e comercialização de plantas medicinais vem sendo incentivados, pela demanda da população pelo uso da fitoterapia, devido aos elevados preços dos medicamentos alopáticos, mas também devido aos efeitos colaterais apresentados por alguns medicamentos sintéticos. Bem como, segundo Correa Junior (2013), devido à preocupação e a busca por produtos com ingredientes naturais obtidos de maneira sustentável. Fatos estes que estimulam e tomam cada vez mais o interesse dos agricultores em ofertar e diversificar a oferta de MACs aos consumidores.

No que tange às espécies mais recorrentes encontradas, em relação aos locais de feiras livres de Chapecó-SC (tabela 2), foram identificadas: Morus sp. (amora branca), Rosmarinus officinalis (alecrim), Equisetum (cavalinha), Aloysia citriodora (cidró), Maytenu ilicifolia (espinheira santa), Mentha sp. (hortelã) e Laurus nobilis (louro), todas encontradas nos dois momentos da pesquisa na feira do Calçadão. Na feira do Centro foram encontradas: Cynara scolymus (alcachofra), Matricaria recutita (camomila), Equisetum sp. (cavalinha), Mentha sp. (hortelã) e Bauhinia forficata (pata de vaca), nos dois momentos da pesquisa. Já para a feira do Bairro Efapi, somente Rosmarinus officinalis (alecrim) foi encontrado em julho e setembro, sendo que as espécies: Morus sp. (amora branca), Plectranthus barbatus (falso-boldo), Matricaria chamomilla (camomila), Aloysia citrodora (cidró), Malva sylvestris (malva), Achyrocline satureoides (marcela) e Salvia officinalis (sálvia) encontradas somente no mês de setembro. Na feira do Bairro São Cristóvão foram encontradas Aloysia citriodora (cidró) e Salvia officinalis (sálvia) no mês de julho. Na feira do Bairro Presidente Médici foi encontrado apenas a Matricaria chamomilla (camomila) no mês de julho, não tendo sido identificada nenhuma espécie no segundo momento de avaliação.

Através das observações realizadas, foi possível constatar que as feiras do bairro Presidente Médici e São Cristóvão são menores, o que justifica o fato de não ter as espécies de MAC disponíveis continuamente aos consumidores. Nestes locais, em geral, os feirantes optam por ofertar outros produtos, tais como frutas, verduras, carnes, lácteos e panificados. Já as feiras do Centro e Calçadão apresentam maior diversidade e oferta das espécies MAC, inclusive com a presença de bancas especializadas na comercialização apenas de partes vegetais, fato que conduz a maior diversidade de espécies comercializadas.

A partir dos resultados, pode-se perceber que, apesar de existir uma diversidade expressiva de espécies vegetais disponíveis para comercialização nas feiras livres de Chapecó, não são muitos os espaços (locais e datas) que dispõem de plantas medicinais, aromáticas e condimentares (MAC). Nesse sentido, é importante avaliar a possibilidade do crescimento deste segmento de comercialização nas feiras livres do município. Assim, esperar-se-ia um aumento na utilização de plantas medicinais, devido às políticas e programas governamentais e ao novo perfil de consumo e demanda da população. Como consequência, maiores quantidades de plantas MAC seriam demandadas, gerando oportunidades para novas alternativas de renda para a agricultura familiar. Para Reis (1996), as plantas medicinais podem ser vistas como fonte de renda para a agricultura familiar, mas também como importantes linhas de ação direcionadas ao desenvolvimento de técnicas de manejo sustentável visando à utilização destas espécies. Fato também destacado por Leite (2009), o qual menciona que a discussão atual sobre o desenvolvimento de fitoterápicos ultrapassa questões científicas, assumindo também uma importância política e econômica, associada ao acesso ao medicamento, como também o aproveitamento sustentável dos recursos naturais e a geração de trabalho e renda.

Tabela 2. Espécies, locais e formas de comercialização de plantas MAC nas feiras livres de Chapecó-SC, 2016.

\begin{tabular}{cccc}
\hline $\begin{array}{c}\text { Nome popular/Nome } \\
\text { científico }\end{array}$ & Local da feira & $\begin{array}{c}\text { Forma de } \\
\text { comercialização }\end{array}$ & Mês \\
\hline Arruda & Calçadão & Mudas & Setembro \\
Ruta graveolens & Presidente & Mudas & Setembro \\
& Médici & Mudas & Setembro \\
& São Cristóvão & Mudas & Julho \\
Camomila & Calçadão & Partes secas & Julho \\
& Centro & Partes secas & Julho e \\
& Presidente & Partes secas & Julho \\
Matricaria chamomilla & Médici & Partes secas & Setembro \\
& Efapi & & Julho e \\
& Calçadão & Partes secas e mudas & setembro
\end{tabular}




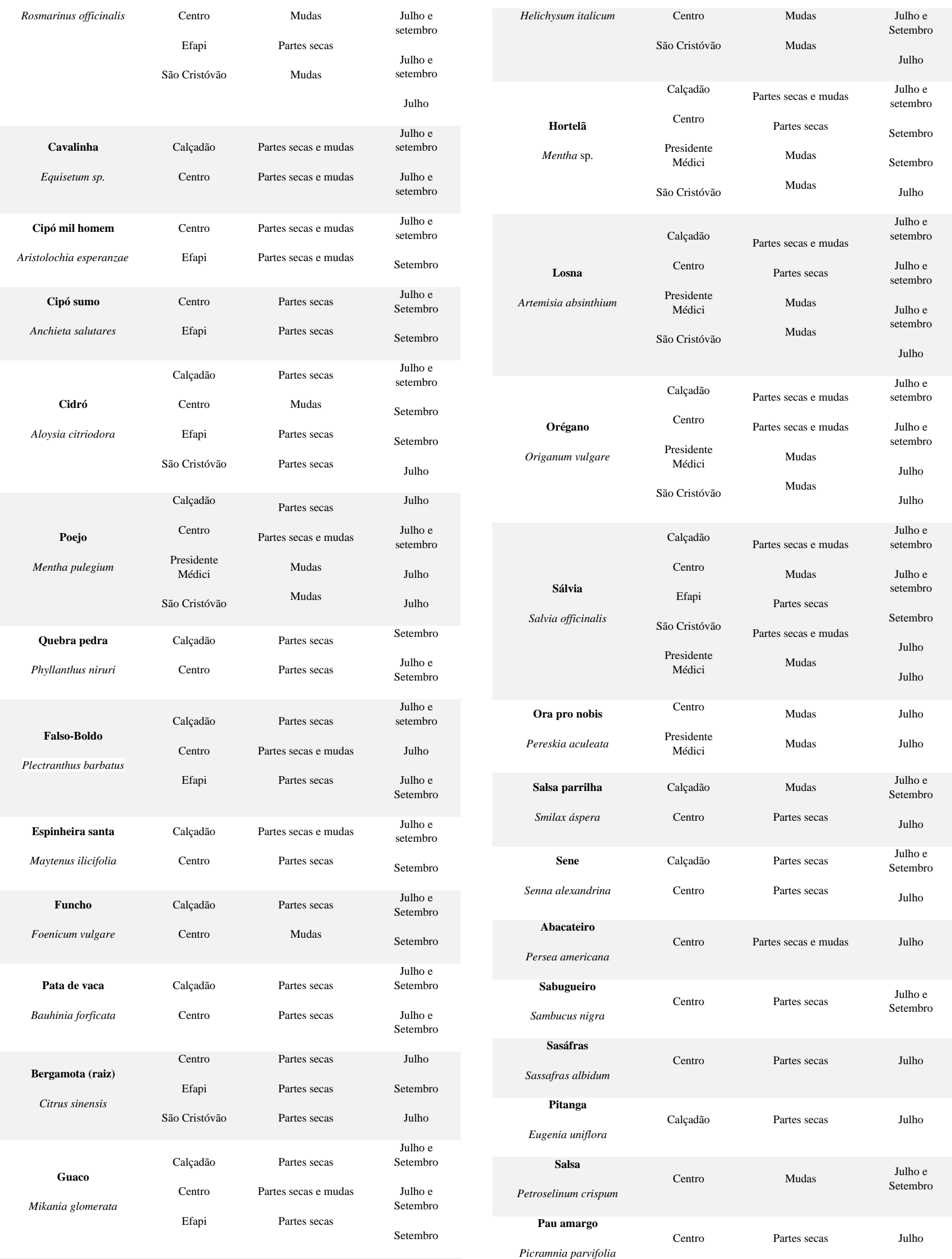




\begin{tabular}{|c|c|c|c|c|c|c|c|}
\hline Chá de bugre & Calçadão & Partes secas & $\begin{array}{l}\text { Julho e } \\
\text { Setembro }\end{array}$ & & & & $\begin{array}{c}\text { Julho e } \\
\text { Setembro }\end{array}$ \\
\hline Casearia sylvestris & Centro & Partes secas & Julho & \multirow{3}{*}{$\begin{array}{c}\text { Marcela } \\
\text { Achyrocline satureioides }\end{array}$} & Calçadão & Partes secas & $\begin{array}{l}\text { Julho e } \\
\text { Setembro }\end{array}$ \\
\hline Alfavaca & \multirow[t]{2}{*}{ Centro } & \multirow[t]{2}{*}{ Partes secas e mudas } & \multirow[t]{2}{*}{$\begin{array}{c}\text { Julho e } \\
\text { Setembro }\end{array}$} & & Centro & Partes secas & Julho \\
\hline бстит ваsticum & & & & & Efapi & Partes secas & Setembro \\
\hline Chá verde & \multirow[b]{2}{*}{ Efapi } & \multirow[b]{2}{*}{ Partes secas } & \multirow[b]{2}{*}{$\begin{array}{l}\text { Julho e } \\
\text { Setembro }\end{array}$} & \multirow[b]{3}{*}{ Origanum majorana } & & & \\
\hline Cammelia sinensis & & & & & Centro & Partes secas e mudas & $\begin{array}{c}\text { Julho e } \\
\text { Setembro }\end{array}$ \\
\hline $\begin{array}{c}\text { Chapéu de couro } \\
\text { Echinodorus grandiflorus }\end{array}$ & Centro & Partes secas & $\begin{array}{l}\text { Julho e } \\
\text { Setembro }\end{array}$ & & $\begin{array}{l}\text { Presidente } \\
\text { Médici } \\
\text { São Cristóvão }\end{array}$ & Mudas & $\begin{array}{l}\text { Julho } \\
\text { Julho }\end{array}$ \\
\hline $\begin{array}{c}\text { Citronela } \\
\text { Cymbopogon winterianus }\end{array}$ & Centro & Mudas & Setembro & $\begin{array}{c}\text { Melissa } \\
\text { Melissa officinalis }\end{array}$ & $\begin{array}{l}\text { Centro } \\
\text { São Cristóvão }\end{array}$ & $\begin{array}{c}\text { Partes secas e mudas } \\
\text { Mudas }\end{array}$ & $\begin{array}{l}\text { Julho } \\
\text { Julho }\end{array}$ \\
\hline Cordão de frade & \multirow[t]{2}{*}{ Centro } & \multirow[t]{2}{*}{ Partes secas } & \multirow[t]{2}{*}{ Julho } & Ipê roxo & Centro & Partes secas & $\begin{array}{l}\text { Julho e } \\
\text { Setembro }\end{array}$ \\
\hline Leonotus nepetaefolia & & & & Tabebuia impetiginosa & Efapi & Partes secas & Setembro \\
\hline $\begin{array}{c}\text { Endro } \\
\text { Anethumgraveolens }\end{array}$ & Calçadão & Partes secas & Julho & $\begin{array}{l}\text { Lavanda } \\
\text { Lavandula }\end{array}$ & $\begin{array}{l}\text { Calçadão } \\
\text { Centro }\end{array}$ & $\begin{array}{l}\text { Mudas } \\
\text { Mudas }\end{array}$ & $\begin{array}{c}\text { Setembro } \\
\text { Julho }\end{array}$ \\
\hline \multirow[t]{2}{*}{$\begin{array}{c}\text { Erva de bicho } \\
\text { Polygonum persicaria }\end{array}$} & \multirow[t]{2}{*}{ Centro } & \multirow[t]{2}{*}{ Partes secas } & \multirow[t]{2}{*}{$\begin{array}{l}\text { Julho e } \\
\text { Setembro }\end{array}$} & Artemisia & Calçadão & Mudas & Setembro \\
\hline & & & & Artemisa vulgaris & Centro & Partes secas & Julho \\
\hline $\begin{array}{c}\text { Erva mate } \\
\text { Ilex paraguariensis }\end{array}$ & Centro & Partes secas & Julho & $\begin{array}{c}\text { Dente de leão } \\
\text { Taraxacum officinale }\end{array}$ & $\begin{array}{l}\text { Calçadão } \\
\text { Centro }\end{array}$ & $\begin{array}{l}\text { Partes secas } \\
\text { Partes secas }\end{array}$ & $\begin{array}{l}\text { Julho } \\
\text { Julho }\end{array}$ \\
\hline $\begin{array}{c}\text { Jaborandi } \\
\text { Pilocarpus jaborandi }\end{array}$ & Calçadão & Partes secas & $\begin{array}{c}\text { Julho e } \\
\text { Setembro }\end{array}$ & Carqueja & Calçadão & Partes secas & Setembro \\
\hline & & & & Baccharis trimera & Centro & Partes secas & Julho \\
\hline $\begin{array}{c}\text { Jatobá } \\
\text { Hymenae acourbaril }\end{array}$ & Centro & Partes secas & Julho & $\begin{array}{c}\text { Chia } \\
\text { Salvia hispânica }\end{array}$ & $\begin{array}{l}\text { Centro } \\
\text { São Cristóvão }\end{array}$ & $\begin{array}{l}\text { Partes secas } \\
\text { Partes secas }\end{array}$ & $\begin{array}{l}\text { Julho } \\
\text { Julho }\end{array}$ \\
\hline Noz pecã & Centro & Partes secas & $\begin{array}{l}\text { Julho e } \\
\text { Setembro }\end{array}$ & Catinga de mulata & Calçadão & Mudas & Setembro \\
\hline Juglans regia & Efapi & Partes secas & Setembro & Tanacetum vulgare & Centro & Partes secas & Julho \\
\hline & São Cristóvão & Partes secas & Julho & Estévia & Calçadão & Partes secas e mudas & $\begin{array}{l}\text { Julho e } \\
\text { Setembro }\end{array}$ \\
\hline Jambolão & $\begin{array}{c}\text { Centro } \\
\text { São Cristóvão }\end{array}$ & $\begin{array}{l}\text { Partes secas } \\
\text { Partes secas }\end{array}$ & $\begin{array}{l}\text { Setembro } \\
\text { Julho }\end{array}$ & Stevia rebaudiana & São Cristóvão & Mudas & Julho \\
\hline Syzygium cumini & Efapi & Partes secas & Setembro & Gervão & Calçadão & Partes secas & $\begin{array}{l}\text { Julho e } \\
\text { Setembro }\end{array}$ \\
\hline Manjericão & Calçadão & Partes secas & Julho & Stachytarpheta cayennensis & Centro & Partes secas & $\begin{array}{l}\text { Julho e } \\
\text { Setembro }\end{array}$ \\
\hline Ocimum basilicum & Centro & Mudas & Setembro & Japecanga & Centro & Partes secas & Julho \\
\hline & São Cristóvão & Mudas & Julho & Smilax japecanga & Efapi & Partes secas & Setembro \\
\hline Sucupira & Centro & Partes secas & $\begin{array}{c}\text { Julho e } \\
\text { Setembro }\end{array}$ & Jurubeba & Calçadão & Partes secas & Setembro \\
\hline Pterodone marginatus & Efapi & Partes secas & Setembro & Solanum paniculatum & Centro & Partes secas & Julho \\
\hline & São Cristóvão & Partes secas & Julho & Tomilho & Calçadão & Partes secas e mudas & $\begin{array}{l}\text { Julho e } \\
\text { Setembro }\end{array}$ \\
\hline Tansagem & Calçadão & Partes secas e mudas & $\begin{array}{l}\text { Julho e } \\
\text { Setembro }\end{array}$ & Thymus vulgaris & Centro & Mudas & Setembro \\
\hline Plantago major & Centro & Partes secas & $\begin{array}{c}\text { Julho e } \\
\text { Setembro }\end{array}$ & Laranjinha do mato & Centro & Partes secas e mudas & Julho \\
\hline & Efapi & Partes secas & Setembro & Eugenia myrciantes & & & \\
\hline & & & & Unha de gato & & & \\
\hline Malva & Calçadão & Partes secas & Setembro & Uncaria tomentosa & Centro & Mudas & Setembro \\
\hline & Centro & Partes secas & Julho e & & & & \\
\hline Malva sylvestris & Efapi & Partes secas & Setembro & $\begin{array}{c}\text { Tarumã } \\
\text { Vitex montevidensis }\end{array}$ & Calçadão & Partes secas & Julho \\
\hline
\end{tabular}




\begin{tabular}{|c|c|c|c|}
\hline $\begin{array}{l}\text { Abóbora danta } \\
\text { Cayaponia tayuya }\end{array}$ & Centro & Partes secas e mudas & Julho \\
\hline $\begin{array}{l}\text { Ginko biloba } \\
\text { Ginkgo biloba }\end{array}$ & Centro & Partes secas & Julho \\
\hline $\begin{array}{l}\text { Amora preta } \\
\text { Rubus ulmifolius }\end{array}$ & Calçadão & Partes secas & $\begin{array}{c}\text { Julho e } \\
\text { Setembro }\end{array}$ \\
\hline Canela & Centro & Partes secas & Setembro \\
\hline Cinnamomum verum & Efapi & Partes secas & Setembro \\
\hline Grapia & Centro & Partes secas & Setembro \\
\hline Apuleia leiocarpa & Efapi & Partes secas & Setembro \\
\hline Louro & Centro & Partes secas & Setembro \\
\hline Laurus nobilis & Calçadão & Partes secas & $\begin{array}{c}\text { Julho e } \\
\text { Setembro }\end{array}$ \\
\hline Menta & Centro & Mudas & Setembro \\
\hline Mentha sp. & São Cristóvão & Mudas & Julho \\
\hline $\begin{array}{c}\text { Mil ramos } \\
\text { Achillea millefolium }\end{array}$ & $\begin{array}{l}\text { Calçadão } \\
\text { Centro }\end{array}$ & $\begin{array}{c}\text { Partes secas } \\
\text { Mudas }\end{array}$ & $\begin{array}{l}\text { Julho } \\
\text { Setembro }\end{array}$ \\
\hline Mestruz & Calçadão & Partes secas & $\begin{array}{l}\text { Julho e } \\
\text { Setembro }\end{array}$ \\
\hline Chenopodium ambrosioides & Centro & Partes secas & Julho \\
\hline $\begin{array}{c}\text { Açoita cavalo } \\
\text { Luehea divaricata }\end{array}$ & Centro & Partes secas e mudas & $\begin{array}{c}\text { Julho e } \\
\text { Setembro }\end{array}$ \\
\hline $\begin{array}{c}\text { Graviola } \\
\text { Annona muricata }\end{array}$ & Centro & Partes secas & Julho \\
\hline $\begin{array}{c}\text { Angico } \\
\text { Parapiptadenia rígida }\end{array}$ & Centro & Partes secas & Setembro \\
\hline $\begin{array}{l}\text { Laranja (casca) } \\
\text { Citrus sinensis }\end{array}$ & Calçadão & Partes secas & Julho \\
\hline $\begin{array}{c}\text { Carapia } \\
\text { Dorstenia brasiliensis }\end{array}$ & Centro & Partes secas & $\begin{array}{c}\text { Julho e } \\
\text { Setembro }\end{array}$ \\
\hline $\begin{array}{c}\text { Cidreira } \\
\text { Cymbopogon citratus }\end{array}$ & Efapi & Partes secas & $\begin{array}{c}\text { Julho e } \\
\text { Setembro }\end{array}$ \\
\hline $\begin{array}{c}\text { Calêndula } \\
\text { Calendula officinalis }\end{array}$ & Calçadão & Partes secas & Setembro \\
\hline $\begin{array}{c}\text { Canfora } \\
\text { Cinnamomum camphora }\end{array}$ & Calçadão & Mudas & $\begin{array}{c}\text { Julho e } \\
\text { Setembro }\end{array}$ \\
\hline $\begin{array}{c}\text { Cambará } \\
\text { Lantana câmara }\end{array}$ & Calçadão & Partes secas & Setembro \\
\hline $\begin{array}{c}\text { Assa peixe } \\
\text { Vernonia polysphaera }\end{array}$ & Centro & Partes secas & Julho \\
\hline $\begin{array}{l}\text { Babosa } \\
\text { Aloe sp. }\end{array}$ & Centro & Mudas & Setembro \\
\hline
\end{tabular}

\begin{tabular}{|c|c|c|c|}
\hline $\begin{array}{c}\text { Eucalipto } \\
\text { Eucalyptus sp. }\end{array}$ & Calçadão & Partes secas & $\begin{array}{c}\text { Julho e } \\
\text { Setembro }\end{array}$ \\
\hline $\begin{array}{c}\text { Fisális } \\
\text { Physalis angulata }\end{array}$ & Centro & Mudas & Setembro \\
\hline Alcachofra & Calçadão & Partes secas & Julho \\
\hline Cynara scolymus & Centro & Partes secas & $\begin{array}{c}\text { Julho e } \\
\text { setembro }\end{array}$ \\
\hline
\end{tabular}

\section{Conclusões}

Foram localizados 10 espaços de realização das feiras livres em Chapecó - SC, totalizando 16 momentos de feiras, distribuídos entre os dias da semana, sendo 2 na terça-feira (Calçadão pela manhã e Bairro Presidente Médici à tarde), 4 na quarta-feira (Centro, Parque das Palmeiras e Bairro São Cristóvão durante a manhã e Bairro Efapi à tarde), 1 na sexta à tarde, na feira do Loteamento Expoente, e 9 no sábado, todas pela manhã, não tendo feira apenas no Loteamento Expoente;

As feiras livres oferecem espécies de plantas medicinais, aromáticas e condimentares tanto na forma de mudas quanto de partes secas. A época do ano influenciou na disponibilidade de algumas espécies de MACs, contudo, de maneira geral, a maioria das espécies não foi influenciada por este fator;

As espécies mais recorrentes encontradas nas feiras livres de Chapecó-SC, de maneira geral, foram: Ruta graveolens, Matricaria chamomilla, Rosmarinus officinalis, Aloysia citriodora, Mentha pulegium, Plectranthus barbatus, Citrus sinensis, Mikania glomerata, Helichysum italicum, Mentha sp., Artemisia absinthium, Salvia officinalis, Ocimum basilicum, Origanum majorana, Achyrocline satureioides, Malva sylvestris, sendo encontradas tanto em mudas como partes secas.

\section{Referências}

AGRA, MF, SILVA, KN, BASÍLIO, IJLD, FREITAS, PF, BARBOSA-FILHO, JM. Survey of medicinal plants used in the region Northeast of Brazil. Revista Brasileira de Farmacognosia, Curitiba, v. 18, p. 472-508, 2008.

ALMEIDA, MZ. Plantas Medicinais. Salvador: UFBA, 2003. 224 p.

COUTINHO, EP, NEVES, HCN, NEVES, HCN, SILVA, EMG. Feiras livres do brejo paraibano: crise e perspectivas. In: ANAIS DO CONGRESSO DA SOCIEDADE BRASILEIRA DE ECONOMIA E SOCIOLOGIA RURAL, 2006, Fortaleza. p. 1 - 12.

DAVID, M, PASA, MC. As plantas medicinais e a etnobotânica em Várzea Grande, MT, Brasil. Interações, Campo Grande, v. 16, p. 1-10, 2015.

\section{JARDIM BOTÂNICO DO RIO DE JANEIRO. Reflora.}

Disponível em: http://floradobrasil.jbrj.gov.br/reflora/PrincipalUC/Principal 
UC.do;jsessionid=F0B6F4CD9223FD24ACD8289112F1954

3. Acesso em: 27 Jan. 2018.

LACERDA, JRC, SOUSA, JS, SOUSA, LCFS, BORGES, MGB, FERREIRA, RTFV, SALGADO, AB, SILVA, MJS. Conhecimento popular sobre plantas medicinais e sua aplicabilidade em três segmentos da sociedade no município de Pombal-PB. Agropecuária científica no semiárido, v. 9, n. 1, p. 14- 23, 2013.

LEITÃO, F, FONSECA-KRUEL, VS, SILVA, IM, REINERT, F. Urban ethnobotany in Petrópolis and Nova Friburgo (Rio de Janeiro, Brazil). Revista Brasileira de Farmacognosia, Curitiba, v. 19, n. 1, p. 333-342, 2009.

LEITE, JPV. Fitoterapia: bases científicas e tecnológicas. São Paulo: Atheneu, 2009. 328 p.

LOURENZANI, WL, LOURENZANI, AEBS, BATALHA, MO. Barreiras e oportunidades na comercialização de plantas medicinais provenientes da agricultura

familiar. Researchgate, v. 1, p. 1-18, 2014.

LUNA, JS. 2006. Estudo de plantas bioativas. Tese Doutorado, Curso de Química, Universidade Federal de Pernambuco, Brasil, pp. 254.

PEREIRA, AM, BERTONI, BW. Plantas como fonte de matéria prima para produção de fitoterápicos. In: FERRO, D: Fitoterapia: conceitos clínicos. São Paulo: Ed. Atheneu, 2008. p. 51-64.

REIS, MS. Manejo sustentado de plantas medicinais em ecossistemas tropicais. In: DI STASI, LC. (Org.): Plantas medicinais: arte e ciência - Um guia de estudo interdisciplinar. 1. ed. São Paulo: USP, 1996, p. 198-201.

SANTOS, EB, DANTAS, GS, SANTOS, HB, DINIZ, MM, SAMPAIO, FC. Estudo etnobotânico de plantas medicinais para problemas bucais no município de João Pessoa, Brasil. Revista Brasileira de Farmacognosia, Curitiba, v. 19, n, 1b, p, 321-324, 2009.

SCHIEDECK, G. Aproveitamento de plantas bioativas. Disponível em: http://www.portaldoagronegocio.com.br/artigo/aproveit amento-de-plantas-bioativas. Acessado em: 06 dez. 2017.

SILVA, SMP, MORAES, IF. Agricultura familiar e o programa Nacional de Fitoterápicos: como a politica publica poderá viabilizar esta cadeia produtiva. Revista Tecnologia \& Inovação Agropecuária, São Paulo, v. 2, p. 67-76, 2008.

Recebido: 18/12/2019

Aceito: 03/03/2020 